\title{
Correction to: Phase 2 Open-Label Trial Investigating Percutaneous Laser Ablation for Treatment of Early-Stage Breast Cancer: MRI, Pathology, and Outcome Correlations
}

\author{
Barbara Schwartzberg, $\mathrm{MD}^{1}$, John Lewin, $\mathrm{MD}^{2}$, Osama Abdelatif, $\mathrm{MD}^{3}$, Jacqueline Bernard, $\mathrm{MD}^{4}$, Hanadi Bu-Ali, \\ $\mathrm{MD}^{5}$, Simon Cawthorn, $\mathrm{Mr}^{6}$, Margaret Chen-Seetoo, $\mathrm{MD}^{7}$, Sheldon Feldman, $\mathrm{MD}^{8}$, Sasirekha Govindarajulu, \\ Miss $^{6}$, Lyn Jones, MD ${ }^{6}$, Arne Juette, MD ${ }^{9}$, Sanjay Kavia, $\mathbf{M D}^{10}$, Robert Maganini, $\mathbf{M D}^{11}$, Simon Pain, Mr', \\ Mike Shere, $\mathrm{MD}^{6}$, Craig Shriver, $\mathrm{MD}^{4}$, Simon Smith, $\mathrm{Mr}^{10}$, Alexandra Valencia, $\mathrm{MD}^{6}$, Eric Whitacre, $\mathrm{MD}^{12}$, and \\ Roger Whitney, MD $^{10}$ \\ ${ }^{1}$ Sarah Cannon Research Institute at Rose Medical Center, Denver, CO; ${ }^{2}$ Women's Imaging Center, Denver, CO; ${ }^{3}$ Tucson \\ Pathology Associates, Tucson, AZ; ${ }^{4}$ Walter Reed National Military Medical Center, Bethesda, MD; ${ }^{5}$ Virginia Piper Cancer \\ Institute, St. Paul, MN; ${ }^{6}$ Southmead Hospital, Bristol, UK; ${ }^{7}$ Herbert Irving Pavilion, Columbia University, New York, NY; \\ ${ }^{8}$ Montefiore Einstein Center for Cancer Care, Bronx, NY; ${ }^{9}$ Norfolk and Norwich University Hospital, Norwich, UK; \\ ${ }^{10}$ Broomfield Hospital, Chelmsford, UK; ${ }^{11}$ St. Alexius Breast Care Center, Bartlett, IL; ${ }^{12}$ Breast Center of Southern \\ Arizona, Tucson, AZ
}

\section{CORRECTION TO: ANN SURG ONCOL (2018) 25:2958-2964 HTTPS://DOI.ORG/10.1245/S10434-018-6623-2}

The article "Phase 2 Open-Label Trial Investigating Percutaneous Laser Ablation for Treatment of Early-Stage Breast Cancer: MRI, Pathology, and Outcome Correlations", written by Barbara Schwartzberg et al., was originally published electronically on the publisher's internet portal (currently SpringerLink) on July 9, 2018, without open access.

With the author(s)' decision to opt for Open Choice, the copyright of the article changed October 2018 to (c) The Author(s) 2018 and the article is forthwith distributed under the terms of the Creative Commons Attribution 4.0 International License http://creativecommons.org/licenses/ by/4.0/), which permits use, duplication, adaptation, distribution and reproduction in any medium or format, as long as you give appropriate credit to the original author(s) and the source, provide a link to the Creative Commons license and indicate if changes were made.

The original article can be found online at https://doi.org/10.1245/ s10434-018-6623-2.

(C) The Author(s) 2018

Published Online: 8 October 2018

B. Schwartzberg, MD

e-mail: scmibs@gmail.com 